Natalia Cediel'

Valeria Conte'

Laura Tomassone $e^{1}$

Donatella Tiberti"

Paolo Guiso "'I

Jaime Romero $^{\mathrm{IV}}$

Luis Carlos Villamil ${ }^{\text {IV }}$

Daniele De Meneghi'

Dipartimento Produzioni Animali,

Epidemiologia ed Ecologia. Facoltà di

Medicina Veterinaria. Universitá degli Studi

di Torino. Turin, Italy

Servizio di Riferimento Regionale di Epidemiologia per la Prevenzione, Sorveglianza e Controllo delle Malattie Infettive. Turin, Italy

III Azienda Sanitaria Locale ASL TO5. ChieriTurin, Italy.

Programa de Medicina Veterinaria. Facultad de Ciencias Agropecuarias. Universidad de la Salle. Bogotá, Colombia

Correspondence:

Natalia Cediel

Calle 104 \# 19a-67, apto. 202 - Santa Bibiana

Bogotá, Colômbia

E-mail: natalia.cediel@unito.it

Received: $8 / 5 / 2011$

Approved: 25/3/2012

Article available from: www.scielo.br/rsp

\section{Risk perception about zoonoses in immigrants and Italian workers in Northwestern Italy}

\author{
Percepção de risco sobre zoonoses \\ em trabalhadores imigrantes e \\ italianos no Noroeste da Itália
}

\begin{abstract}
OBJECTIVE: To assess factors associated with a low risk perception of zoonoses and to identify the gaps in knowledge about transmission and prevention of zoonoses in immigrant and Italian workers.
\end{abstract}

METHODS: A cross-sectional study with 175 workers in the agro-livestock and agro-food industry in Piemonte, Italy, was carried out. Data were collected with a semi-structured questionnaire based on knowledge, attitudes and practices (KAP) survey. We calculated proportions and used chi-square tests and odds ratios to assess associations. Eight individual interviews with key informants on immigration and public health in Piemonte were carried out.

RESULTS: Participants were 82 (47\%) Italians and 93 (53\%) immigrants. Immigrants were from Romania, Morocco, Albania, India, China, Argentina, Peru, Macedonia, Ivory Coast, Ukraine and Colombia. The study revealed significant differences in risk perception at work $(p=0.001)$. We found associations between "not having correct knowledge about zoonoses" and the following variables: i. "being immigrant" $\mathrm{OR}=4.1(95 \% \mathrm{CI} 1.7 ; 9.8 \mathrm{p} \leq 0.01)$; ii. "working in the livestock industry" $\mathrm{OR}=2.9(95 \% \mathrm{CI} 1.2 ; 15.4 \mathrm{p}=0.01)$; and iii. "being an unqualified worker" $\mathrm{OR}=4.4(95 \% \mathrm{CI} 2.9 ; 15.4 \mathrm{p} \leq 0.01)$. Another strong association was found between being immigrant and having a low job qualification $\mathrm{OR}=6.7$ (IC95\% $2.9-15.4 \mathrm{p} \leq 0.01$ ). Asian immigrants were the group with the highest frequency of risky behaviours and the lowest level of knowledge about zoonoses.

CONCLUSIONS: Our results indicate that there were differences in risk perception of zoonoses between the groups participating in our study. These results suggest that immigrant status can be considered a risk factor for having lower risk perception and lower level of knowledge of zoonoses at work. There is a relationship between this specific knowledge of zoonoses and lack of training and instruction among migrant populations. Our results stress the need for developing education programs on zoonoses prevention among the immigrant population in Piemonte, Italy.

DESCRIPTORS: Health Knowledge, Attitudes, Practice, Animal Husbandry, Zoonoses. Perception. Occupational Risks. Cross-Sectional Studies. 


\section{RESUMO}

OBJETIVO: Analisar fatores associados à baixa percepção de risco de zoonoses e identificar as lacunas no conhecimento sobre a transmissão e prevenção de zoonoses em trabalhadores imigrantes e italianos.

MÉTODOS: Estudo transversal com 175 trabalhadores da indústria agropecuária e agroalimentar em Piemonte, Itália. Os dados foram obtidos por meio de questionário semiestruturado baseado em estudo sobre conhecimentos, atitudes e práticas. Foram calculadas proporções, com uso de teste qui-quadrado e odds ratio para estimar associações. Oito entrevistas individuais com informantes-chave em matéria de imigração e saúde pública foram realizadas.

RESULTADOS: Cerca de 47\% dos trabalhadores eram italianos e 53\%, imigrantes, provenientes da Romênia, Marrocos, Albânia, Índia, China, Argentina, Peru, Macedônia, Costa do Marfim, Ucrânia e Colômbia. Houve diferenças significativas na menor percepção do risco no trabalho $(p=0,001)$. Observou-se associação entre falta de conhecimentos corretos sobre zoonoses e ser imigrante $(\mathrm{OR}=4,1$; IC $95 \% 1,7 ; 9,8 ; \mathrm{p} \leq 0,01)$, trabalhar na indústria pecuária $(\mathrm{OR}=2,9 ; \mathrm{IC} 95 \% 1,2 ; 6,8 ; \mathrm{p}=0,01)$ e ser um trabalhador não qualificado $(\mathrm{OR}=4,4$; IC95\% 1,2;15,4; $\mathrm{p}=0,01)$. Outra forte associação ocorreu entre ser imigrante e ter emprego de baixa qualificação $(\mathrm{OR}=6,7$; IC95\% 2,9;15,4; $\mathrm{p} \leq 0,01)$. Maior frequência de comportamentos de risco e menor nível de conhecimento sobre zoonoses foram encontrados no grupo dos imigrantes asiáticos.

CONCLUSÕES: Foram observadas diferenças na percepção de risco de zoonoses entre os grupos participantes. O status de imigrante pode ser considerado fator de risco para ter baixa percepção de risco e menor nível de conhecimento das zoonoses no trabalho. Existe relação entre esse conhecimento específico de zoonoses e falta de formação e instrução entre as populações migrantes. É necessário desenvolver programas de educação sobre a prevenção de zoonoses entre a população imigrante.

\section{DESCRITORES: Conhecimentos, Atitudes e Prática em Saúde, Criação de Animais Domésticos, Zoonoses. Percepção. Riscos Ocupacionais. Estudos Transversais.}

\section{INTRODUCTION}

Emerging infectious diseases are the result of a convergence of social, political, environmental and economic factors, whether the diseases are new, re-emerging, or becoming endemic. ${ }^{a}$ Mass migrations of people, food consumption patterns and hygiene practices are among the social factors that influence the emergence of infectious diseases and zoonoses. ${ }^{1}$ Zoonotic diseases, which are those that are shared between animals and people, pose a significant public health threat in both developing and developed countries because they have high incidence rates and cause significant morbidity and mortality. ${ }^{2,3}$ Immigrant populations face several disadvantages in confronting diseases, such as cultural, language and job barriers, lack of family support, and limited access to the local sanitary services. ${ }^{1,4-7}$

There is information available about the health status of the immigrant community in Piemonte, ${ }^{\text {b,c }}$ but little is known about the risk perception of zoonoses among

a Food and Agriculture Organization of the United Nations, World Health Organization, World Organisation for Animal Health. Report of the WHO/FAO/OIE joint consultation on emerging zoonotic diseases: in collaboration with the Health Council of the Netherlands; 2004 May 3-5; Geneva, Switzerland. Geneva; 2004[cited 2011 Nov]. Available from: http://whqlibdoc.who.int/hq/2004/WHO_CDS_CPE_ ZFK_2004.9.pdf

${ }^{\mathrm{b}}$ Istituto di Ricerche Economiche e Sociali. Rapporto regionale 2006: Osservatorio sulla immigrazione in Piemonte, Immigrazione in Piemonte. Torino; 2007 [cited 2009 Feb].

c Costa G, Gnavi R. La salute in Piemonte - misure e problemi per la salute e la sanità. capitolo 2. Torino: Regione Piomonté; 2006[cited 2009 Feb]. Available from: http://www.regione.piemonte.it/sanita/ep/salute2006/pdf/capitolo2.pdf 
exposed workers in this field. ${ }^{\mathrm{d}}$ Experts $^{8, \mathrm{e}}$ conclude that perception of risk is likely to vary between different countries, depending on what the news media chose to report, what people chose to discuss, what cultural norms were perceived as important, and what technical and legal opportunities existed for the control and regulation of risk. Risk perception was hypothesized to be an effect of cultural, environmental, and governmental influences. $^{\mathrm{e}}$

This study aimed to analyze the association between immigration and low perception of risk of zoonoses and to identify the gaps in knowledge of zoonoses between immigrant and Italian workers in the livestock and agrofood chain industries. This preliminary information may help improve strategies of risk communication and prevention programs on zoonoses for workers in Northwestern Italy.

\section{METHODS}

Cross-sectional survey using a questionnaire on knowledge, attitudes and practice (KAP) conducted among immigrants working in livestock production and in the food chain industry in six administrative provinces of Piemonte, Italy. The KAP approach was used because the World Health Organization (WHO) promoted a Knowledge, Attitude, Beliefs and Practices (KABP) framework as a tool to improve disease prevention strategies in different cultures around the world in $1989 .{ }^{\mathrm{f}}$

A non probabilistic voluntary sampling design was used. The participants were selected by contacting the official state veterinarians working in the sanitary/health inspection of livestock sector (cattle, pig, goat and poultry farms) and food-chain sector (slaughterhouses, meat processing and dairy/ cheese production plants). The veterinarians provided information about the workplace location of potential study participants and helped the investigators by contacting the employers, to then gain official permission to reach the workers in six Piemonte provinces (Turin, Cuneo, Vercelli, Asti, Alessandria, Verbano-Cusio-Ossola). We included immigrants and Italians based on the criteria: exposure to animals, or animal fluids or animal products at work; ability to understand and speak Italian language (in the case of immigrants); voluntary acceptance to join the study from both the employee as well as the employer of the farm/plant. We excluded farms/plants which did not answer our invitation in a six-month period. We decided not to exclude participants who, because of language barrier, did not understand a few questions but were able to understand the majority of them.

A semi-structured questionnaire with three categories of questions was designed and administered between July 2008 and July 2009. Questions referred to: general information of participants, health status, risk perception at work, use of Personal Protective Equipment (PPE) at work, eating habits and hygiene behaviours, hypothetical risky situations, and knowledge on transmission of zoonoses.

The sample size of immigrants to be interviewed was calculated by using the software Epidat 3.1, 95\% confidence interval (CI), an expected prevalence of $50 \%$, and the acceptable absolute error at $10 \%$. The target population were the 2.853 foreigners working in the livestock and food chain industry in Piemonte. A sample size of 93 immigrants was estimated. A similar group of Italian participants working in the same field (not necessarily working in the same location) was also recruited $(n=82)$, to evaluate the risk factor of being immigrant.

The same operators (NC and VC) administered all the questionnaires and experts interviews. Data were collected and stored using Windows MS Excel ${ }^{\circledR}$. Data analysis was performed using Epidat (version 3.1). We calculated the proportions to determine the status of each indicator, and used statistical tests (chi-square, odds ratio and Mantel-Haenszel adjusted OR, respectively) to assess associations, using a 95\% confidence level $(\alpha=0.05)$. A total of 175 questionnaires were administered to immigrants (93) and Italian (82) workers employed in the food chain sector and livestock industry.

We also carried out eight individual expert interviews with key informants and local researchers on immigration and public health in Piemonte, physicians specialized in infectious diseases and zoonoses, and professionals at local healthcare services.

\section{RESULTS}

Around $82.0 \%$ of respondents were men and $18.0 \%$ were women; $47.0 \%$ were Italians and $53.0 \%$ were immigrants. Immigrants were from Romania (39.0\%), Morocco (17.0\%), Albania (14.0\%), India (12.0\%); $16.0 \%$ were from China, Argentina, Peru, Macedonia, Ivory Coast, Ukraine and Colombia. About 66.0\% were married and $34.0 \%$, single; $65.0 \%$ worked in

\footnotetext{
${ }^{d}$ Cediel N, De Meneghi D. Public perception about zoonoses and prevalence of zoonotic diseases in latin-american immigrants living in northwestern Italy - building a model of ecosystem health. Project Final report. Torino: Università degli Studi di Torino / Fondazione CRT World Wide Style; 2009. p.34.

e Sjöberg L, Moen B, Rundmo T. Explaining risk perception. An evaluation of the psychometric paradigm in risk perception research. Norwegian: University of Science and Technology; 2004 (Rotunde publications, 84).

${ }^{f}$ World Health Organization. Knowledge, attitudes, beliefs and practices on AIDS. Global Programme on AIDS Social and Behavioural Research Unit. Geneva; 1989.
} 
Turin province and Cuneo. The majority (around $70.0 \%$ ) was 25 to 45 years. Most of the workers $(60.3 \%)$ were employed in the livestock industry (breeding dairy cows, fattening calves, pigs, horses) and $39.7 \%$ belonged to the food chain industry (cattle slaughter, pork and poultry cutting/processing, dairy and catering). Around $70.0 \%$ were generic workers without a specific qualification for the job; $10.0 \%$ were trained or skilled workers (Table 1).

Data analysis showed significant differences regarding gender (a higher proportion of male migrant workers than Italian males: $89.0 \%$ and $73.0 \%$ respectively; $\mathrm{p}=0.010$ ); job qualification (more unqualified migrant workers than unqualified Italian ones: $87.0 \%$ and $51.0 \%$ respectively; $\mathrm{p} \leq 0.01$ ); province (Italians worked more often in Torino province than immigrants: $45.0 \%$ and $24.0 \%$ respectively; $\mathrm{p} \leq 0.01$ ).

Fifty five percent of respondents considered their health status as excellent, $37.0 \%$ considered it good, $6.0 \%$ felt it was weak or poor. The main health problems emerging among those who declared a poor health status were: dermatitis, skin allergies, ulcers, abortion, appendicitis, hypertension, flu, sore teeth, headache or injuries. The most widely used medical service was the family doctor (65.0\%). However, Indian/Asian respondents claimed to have more confidence in traditional medicine than in Western medicine.

Regarding the question "What is the chance of having health problems at work?", $71.0 \%$ of the employees pointed out "low possibility" and "none", arguing that "You just have to pay attention to the procedures". Many of the participants referred traumatic injuries with knifes and contact with animal blood (24\%), $11 \%$ stating mechanical and physical risks as animal kicks and falls, and backaches due to cold environments. The majority of respondents (97\%) said that they were supplied with, and regularly used, all elements necessary for protection. However, not all employers provided these tools to livestock industry workers, nor showed them which ones are needed. Three respondents (Romanian workers on a farm) claimed to work without protective elements, arguing: "My hands are my gloves". Table 2 presents the risk perception at work, health perception, knowledge of use of Personal Protective Elements (PPE) between Italians and immigrant groups.

There were significant differences regarding the risk perception at work. Migrant workers perceived that they had no risky activities at work with a higher

Table 1. Sociodemographic characteristics of migrant and Italian workers. Piemonte, Italy, 2008-2009.

\begin{tabular}{|c|c|c|c|c|c|}
\hline Variable & Italian $(95 \% \mathrm{Cl})$ & $\mathrm{n}$ & Migrant $(95 \% \mathrm{Cl})$ & $\mathrm{n}$ & $p<0.05$ \\
\hline \multicolumn{6}{|l|}{ Gender } \\
\hline Male & $73 \%(62 ; 82)$ & 60 & $89 \%(81 ; 95)$ & 83 & 0.010 \\
\hline \multicolumn{6}{|l|}{ Marital status } \\
\hline Married & $67 \%(55 ; 76)$ & 55 & $65 \%(55 ; 75)$ & 61 & 0.962 \\
\hline \multicolumn{6}{|l|}{ Age (years) } \\
\hline$<25$ & $14 \%(7 ; 23)$ & 11 & $15 \%(8 ; 24)$ & 14 & \\
\hline 25 to 35 & $31 \%(21 ; 42)$ & 25 & $43 \%(33 ; 54)$ & 40 & 0.07 \\
\hline 35 to 45 & $32 \%(22 ; 43)$ & 26 & $32 \%(23 ; 43)$ & 30 & \\
\hline$>46$ & $23 \%(15 ; 34)$ & 19 & $10 \%(4 ; 18)$ & 9 & \\
\hline \multicolumn{6}{|l|}{ Field of work } \\
\hline Food chain & $38 \%(27 ; 50)$ & 31 & $41 \%(31 ; 51)$ & 38 & \\
\hline Livestock & $62 \%(50 ; 72)$ & 50 & $59 \%(48 ; 69)$ & 55 & 0.847 \\
\hline \multicolumn{6}{|l|}{ Job qualification } \\
\hline Skilled worker & $38 \%(27 ; 49)$ & 31 & $11 \%(4 ; 17)$ & 10 & \\
\hline Unskilled worker & $51 \%(40 ; 63)$ & 42 & $87 \%(80 ; 94)$ & 81 & $<0.01$ \\
\hline Unknown & $11 \%(4 ; 18)$ & 8 & $2 \%(0,3 ; 8)$ & 2 & \\
\hline \multicolumn{6}{|l|}{ Province } \\
\hline Alessandria & $7 \%(3 ; 15)$ & 6 & $15 \%(8 ; 24)$ & 14 & \\
\hline Asti & $11 \%(5 ; 20)$ & 9 & $17 \%(10 ; 26)$ & 16 & \\
\hline Cuneo & $28 \%(19 ; 39)$ & 23 & $34 \%(25 ; 45)$ & 32 & $<0.01$ \\
\hline Torino & $45 \%(34 ; 56)$ & 37 & $24 \%(15 ; 34)$ & 22 & \\
\hline Verbania & $5 \%(1 ; 12)$ & 4 & $10 \%(4 ; 18)$ & 9 & \\
\hline Vercelli & $4 \%(1 ; 10)$ & 3 & $0 \%$ & 0 & \\
\hline
\end{tabular}


frequency than Italians $(43.0 \%$ and $20.0 \%$ respectively; $\mathrm{p} \leq 0.01$ ); Italians considered they faced high risk activities at work at a higher frequency compared to migrant workers $(38.0 \%$ and $18.0 \%$ respectively; $\mathrm{p} \leq 0.01$ ) (Table 2).

About $78.0 \%$ of participants did not eat raw eggs for personal preference or religious reasons (Indians/ Asians) or because they did not feel it safe for their own health. Five percent claimed to eat raw eggs every day because "They give extra energy". As for fresh milk, $43.0 \%$ drank pasteurized milk, and $21.0 \%$ said they always boiled it before drinking because it was safer; $12.0 \%$ reported drinking fresh raw milk.

The majority of respondents $(90.0 \%)$ agreed with the statement "Animals, as well as children, should always be vaccinated and treated with anti-parasites against communicable diseases". When asked why they answered that way, $41.0 \%$ responded that the reason was "To avoid diseases," $6.0 \%$ responded "Because veterinarian told me to do it" and $2.0 \%$ did not understand what vaccination means.

Overall, $87.0 \%$ of respondents said that they always washed their hands after going to the toilet and always before eating. Some short and simple hypothetical situations were proposed to encourage conversation. The first situation concerned the presence of ticks on humans and the behaviour to be applied in case of infestation: the majority of respondents stated that the tick should be removed (55.0\%) "Because it causes a nuisance and because it may transmit diseases".

The second situation concerned an episode of animal abortion in livestock at a farm. Most workers (76.0\%) would call the vet or the head company and then remove the foetus carefully, but they did not answer why they behaved this way.

The last situation concerned the presence of faeces of dogs and cats in places where children play. About $89.0 \%$ said that one should always take them away because "Faeces may transmit diseases", "They make the park dirty", and "It's good mannered to do so".

All respondents were asked to indicate whether they knew about diseases that can be trasmitted between animals and humans: $79.0 \%$ answered "Yes", but they did not give any examples; $96.0 \%$ said they had never had diseases transmitted from animals; $1.0 \%$ of immigrants and $3.0 \%$ of Italians reported having had

Table 2. Risk perception at work and health perception among migrant and Italian workers. Piemonte, Italy, 2008-2009.

\begin{tabular}{|c|c|c|c|c|c|}
\hline Variables & Italian $(95 \% \mathrm{Cl})$ & $\mathrm{n}$ & Migrant $(95 \% \mathrm{Cl})$ & $\mathrm{n}$ & $\mathrm{p}<0.05)$ \\
\hline \multicolumn{6}{|c|}{ Risk perception at work } \\
\hline None & $20 \%(12 ; 30)$ & & $43 \%(33 ; 54)$ & 40 & \multirow{4}{*}{$<0.01$} \\
\hline Low & $42 \%(31 ; 54)$ & 16 & $37 \%(27 ; 47)$ & 34 & \\
\hline High & $38 \%(28 ; 50)$ & 34 & $18 \%(11 ; 26)$ & 17 & \\
\hline Very high & $0 \%$ & 31 & $2 \%(0,3 ; 7)$ & 2 & \\
\hline \multicolumn{6}{|c|}{ Perceived health status } \\
\hline Excellent & $63 \%(51 ; 73)$ & 51 & $48 \%(38 ; 59)$ & 45 & \multirow{3}{*}{0.07} \\
\hline Good & $28 \%(19 ; 39)$ & 23 & $45 \%(35 ; 56)$ & 42 & \\
\hline Poor & $9 \%(3 ; 17)$ & 7 & $6 \%(2 ; 13)$ & 6 & \\
\hline \multicolumn{6}{|c|}{ Use of Personal Protective Equipment } \\
\hline Yes & $100 \%$ & 82 & $96 \%(89 ; 99)$ & 89 & 0.167 \\
\hline
\end{tabular}

Table 3. Factors associated with immigration status according to level of knowledge on zoonoses. Piemonte, Italy, 2008-2009.

\begin{tabular}{lcccccc}
\hline Variables & Italian & $\mathrm{n}$ & Migrant & $\mathrm{n}$ & $\mathrm{OR}(95 \% \mathrm{Cl})$ & $\mathrm{p}<0.05$ \\
\hline Eating raw eggs & $14 \%$ & 10 & $15 \%$ & 13 & $1.0(0.4 ; 2.6)$ & 0.97 \\
Drinking fresh milk & $18 \%$ & 13 & $17 \%$ & 11 & $0,8(0.3 ; 2.1)$ & 0.98 \\
Frequent hand washing & $100 \%$ & 82 & $93 \%$ & 87 & - & 0.05 \\
Frequent food washing & $94 \%$ & 76 & $86 \%$ & 80 & $2,4(0.8 ; 7.2)$ & 0.15 \\
Agree that animals should be vaccinated and deparasitized & $89 \%$ & 72 & $85 \%$ & 79 & $1.4(0.5 ; 3.4)$ & 0.50 \\
Agree that animal feces should be removed from public play areas & $89 \%$ & 72 & $89 \%$ & 83 & $0.9(0.3 ; 2.5)$ & 0.86 \\
Indifference/ risky attitude in animal abortion situation & $60 \%$ & 48 & $85 \%$ & 79 & $4.1(2.0 ; 8.7)$ & $<0.01$ \\
Risky behavior in tick bite situation & $49 \%$ & 39 & $41 \%$ & 38 & $0.7(0.4 ; 1.3)$ & 0.334 \\
Adequate knowledge of diseases shared by animals and humans & $90 \%$ & 74 & $68 \%$ & 64 & $4.1(1.7 ; 9.8)$ & $<0.01$ \\
\hline
\end{tabular}


parasitic diseases but did not clarify whether these were of zoonotic origin.

The proportion of persons who did not know about diseases shared between animals and humans was four times higher in immigrants than in Italians $(\mathrm{OR}=4.1$; $\mathrm{p} \leq 0.01)$. The proportion of people who described risky behaviours when facing an animal abortion situation was four times higher in immigrants than in Italian workers $(\mathrm{OR}=4.1 ; \mathrm{p} \leq 0.01)$. Associations were found between not having correct knowledge about zoonotic diseases and the variables: working in the livestock industry $(\mathrm{OR}=2.9 ; \mathrm{p}=0.01)$; being unqualified workers $(\mathrm{OR}=4.4 ; \mathrm{p}=0.01)$ (Table 3$)$.

There was strong association between being an immigrant and having a low job qualification $(\mathrm{OR}=6.7$ $\mathrm{p} \leq 0.01)$. The differences in knowledge on zoonoses between Italians and immigrants persisted after adjusting for job qualification. The crude and Mantel-Haenszel adjusted OR were 4.2 (IC95\% 1.8;9.8) and 2.6 (IC95\% $1.1 ; 6.4)$, respectively.

Asian immigrants had a higher frequency of many of the practices deemed most risky among the immigrant groups as well as a higher proportion of answers indicating a low level of knowledge about zoonoses. The groups that responded with answers indicating a high level of knowledge on zoonoses were the Latin American workers, followed by the Western European (Italian) ones.

When asked about examples of zoonoses, participants cited the diseases: mycotic dermatitis (Asian milkers); rabies (Romanian and Moroccan workers); influenza and respiratory diseases (workers in pig farms); echinococcosis (an ex-shepherd who then worked in a cheese industry); psittacosis (an Argentinean veterinarian); toxoplasmosis, BSE and brucellosis (veterinarian working in food quality control); parasitic diseases, salmonellosis, leptospirosis and campylobacteriosis (a Peruvian veterinarian working in pig farms).

According to experts interviewed, the under-reporting of cases of zoonoses in Piemonte could be estimated in $80 \%$, and the priority zoonoses to focus surveillance activities are: tuberculosis, salmonellosis, campylobacteriosis, listeriosis, leishmaniosis, leptospirosis, brucellosis, toxoplasmosis, trypanosimiasis and rickettsiosis.

\section{DISCUSSION}

The present study provides the first systematic assessment on risk perception of zoonoses focused on immigrants and Italian workers in the livestock and food chain industries in Piemonte, Italy.

Our results suggest an association between being an immigrant and a lower perception of risk of zoonoses, as well as less knowledge about zoonoses in professional activities. The results were in accordance with Mavroidi (2008), ${ }^{3}$ who indicated that immigration is an important cause of health disadvantages in the country of destination, mainly because of their limited access to the local sanitary services and the low accessibility to health education programs. The results confirm previous studies reporting that place of work $(p<0.01)$, educational attainment $(\mathrm{p}<0.01)$, and training status on rearing or handling of livestock $(\mathrm{p}<0.01)$ were consistent and important determinants of the level of knowledge about, attitude to, and use of preventive measures against zoonoses. ${ }^{9}$ The observed association between unqualified work and risk perception of zoonoses suggests that there may be a relationship between this specific knowledge and lack of training and instruction among migrant populations working in the livestock industry.

"Riskiness" means more to people than "expected number of fatalities", because they have a broader conception of risk than experts. ${ }^{8}$ Under the psychometric paradigm, it is assumed that risk is subjectively defined by individuals, who may be influenced by a wide array of psychological, social, institutional, and cultural factors. ${ }^{\mathrm{e}}$ There were differences in risk perception of zoonoses between groups in our study. These differences may be explained by the influence of the culture itself, the outcome feedback from previous risky situations, the environment, the previous knowledge on the topic, among others. ${ }^{8,10,11}$ Although it is not possible to assure that the differences observed are only explained by culture, the local experts on immigration and health interviewed in our study stated that, sometimes, immigrants consider that infectious diseases have inter-human transmission and there is no perception that animals can infect humans, thus increasing the risk to contract a zoonotic disease. The experts said that the eating habits of immigrants represent a risk factor, especially regarding the methods of food preservation in certain immigrant communities. The risks often reside in the last phase (storage and conservation) of the food chain or imported food from countries where health regulations are less rigid than those in force in Italy.

The open questions in our questionnaire were useful to understand the behavior and attitudes of workers facing risky situations in spite of the difficulty to measure them. In some of the hypothetical questions, participants were hesitant in their answers because they were unsure about how they would behave or probably because they did not understand the questions. According to Launiala (2009), ${ }^{10}$ questions related to safety behaviors and practices are interlinked with the person's knowledge, beliefs, emotions, and values, and they are either positive or negative. The risk perception and behavior towards zoonoses can be influenced more by habits and customs than by specific knowledge on transmission mechanisms of zoonoses. It is possible 
to have an appropriate level of knowledge about the risk, but this may not be reflected in the daily practices at work. To regulate public health policy, the health authorities need to understand how people think and how people respond to risk. Without such understanding, well-intended policies may be ineffective. ${ }^{\mathrm{e}}$

This study have some methodological limitations. In two questions (hand washing and food washing), there was a high proportion of agreement among responses. One explanation could be that there is indeed strong agreement, cultural homogeneity or high awareness on hygiene practices among participant workers; however, it is also possible that the question formulation could influence attitudes towards favorable, "agreeing" answers. The voluntary sampling was chosen because, in practice, it was the only feasible way to reach immigrant workers employed in these sectors; the inference of our results is limited to immigrants working in the same sector in Piemonte. The contact between the local veterinarian and the potential study participants was a key factor for conducting the study, because it was not possible to gain access to a dataset of these workers a priori. Thus, we had to rely on the cooperation of the official state veterinarians in the provinces where the research was conducted. A certain level of selection bias is admitted, but it was unfeasible to amend the employer's lack of interest on this topic (zoonoses), so they did not allow reaching employees. At a certain point, answers were repetitive and showed no great variability between them. Therefore, with our sample of 175 respondents, we are close to the full picture of possible answers for this population.

The linguistic barriers between the respondents and the interviewers could have induced a certain level of bias in the study. Not all the participants were fluent in Italian (or English if they did not speak Italian), which in some situations made it difficult to ask the questions, especially those regarding the hypothetical risky situations. Special attention must be paid to the language barriers that immigrant communities face in Italy, particularly because during the field work of this study we noted that Asian immigrants (workers from China and India) have difficulties to understand Italian language, making it hard to communicate with them. The lack of understanding of the questions could be an explanation for the answers given by Asian immigrants, who had higher frequencies for some risky behaviors. These results showed that the difficulty in speaking Italian may interfere with the participants understanding about zoonotic diseases and their prevention. This is in accordance with Chubachi (2002), ${ }^{4}$ who affirmed that lack of effective communication with immigrants does play an important role on behavior and attitudes concerning the disease. This fact can generate an obstacle for successful prevention programs on this population.

Public attitudes towards zoonoses play a major role for a successful implementation of prevention, control and management measures of zoonoses. ${ }^{10}$ Behavior changes are difficult to induce and sustain, even in situations in which interventions are evidence-based, practical, affordable and acceptable. ${ }^{12}$ Despite the differences between both groups, Italians as well as immigrants need educational activities on prevention measures of zoonoses. ${ }^{13}$ It is important to prioritize epidemiologic surveillance systems on zoonoses at a regional level, as well as to focus on prevention training programs in regions where there is an important migratory flow of workers in rural activities. Conducting training and providing educational material in the native language of the immigrants is necessary.

\section{ACKNOWLEDGEMENTS}

To the Assessorato alla Sanità, Dipartimento Prevenzione, Regione Piemonte; to Public health officers and veterinarians of the Local Heath Units Turin, Asti, Alessandria, and Cuneo provinces; to Infectious Diseases referral Hospitals; specialist on immigration and health and Turin Owners/directors and workers of farms, milking plants, abattoirs, meat processing plants, etc., who agreed to participate in our study. To Mrs. Marcela Olmedo, volunteers from ISI (Informazione Sanitaria Immigrati), cultural mediators, and the Caritas diocesana torinese. To Dr. Javier Narvaez, Mrs. Christina Kappaz and Mr. Adir Glick for their valuable contribution at editing and supporting this manuscript. 


\section{REFERENCES}

1. Ramakrishna J, Weiss MG. Health, illness, and immigration. East Indians in the United States. West J Med. 1992;157(3):265-70.

2. Pan American Health Organization. Zoonoses and communicable diseases common to man and animals. 3.ed. Washington, D.C: PAHO; 2001.

3. Mavroidi N. Transmission of zoonoses through immigration and tourism. Vet Ital. 2008;44(4):651-6.

4. Chubaci RYS, Merighi MAB. A comunicação no processo da hospitalização do imigrante japonês. Rev Latino-Am Enfermagem. 2002;10(6):805-12. DOI:10.1590/S0104-11692002000600009

5. Jansà JM, García de Olalla P. Salud e inmigración: nuevas realidades y nuevos retos. Gac Sanit. 2004;18(Suppl 1):207-13. DOI:10.1157/13062528

6. Suurmond J, Seeleman C. Shared decisionmaking in an intercultural context Barriers in the interaction between physicians and immigrant patients. Patient Educ Couns. 2006;60(2):253-9. DOI:10.1016/j.pec.2005.01.012

7. Zunzunegui M, Forster M, Gauvin L, Raynault M, Willms JD. Community unemployment and immigrants' health in
Montreal. Soc Sci Med. 2006;63(2):485-500. DOI:10.1016/j.socscimed.2006.01.004

8. Slovic P. Risk Perception. Science. 1987;36(4799):280-5. DOI:10.1126/science.3563507

9. Umar AS, Nura A. Training needs and risk assessment among farmers and animal handlers on zoonoses in Sokoto metropolis. Sokoto, Nigeria. Niger Postgrad Med J. 2008;15(3):168-74.

10. Launiala A. How much can a KAP survey tell us about people's knowledge, attitudes and practices? Some observations from medical anthropology research on malaria in pregnancy in Malawi. Anthropol Matters. 2009;11(1).

11. Sjoberg L. Factors in risk perception. Risk Anal. 2000;20(1):1-11. DOI:10.1111/0272-4332.00001

12. Macpherson CNL. Human behaviour and the epidemiology of parasitic zoonoses. Int J Parasitol. 2005;35(11-12):1319-31. DOI:10.1016/j.ijpara.2005.06.004

13. Panter-Brick C, Clarke SE, Lomas H, Pinder M, Lindsay SW. Culturally compelling strategies for behaviour change: a social ecology model and case study in malaria prevention. Soc Sci Med. 2006,62(1):2810-25. DOI:10.1016/j.socscimed.2005.10.009

Study funded by Regione Piemonte, Progetto Ricerca Sanitaria Finalizzata 2007-2008, and from World Wide Style-WWS Project, UNITO / Fondazione CRT, Torino (Process $n^{\circ} 3702 / 2008$ ).

The authors declare that there are no conflicts of interest. 